J. Lake Sci. (湖泊科学), 2012, 24(2):287-293

http: //www. jlakes.org. E-mail : jlakes@niglas.ac.cn

(C) 2012 by Journal of Lake Sciences

\title{
洞庭湖湿地土壤种子库特征及其与地表植被的相关性”
}

\author{
侯志勇, 陈心胜, 谢永宏 ${ }^{* *}$, 李 旭
}

(中国科学院亚热带农业生态研究所,亚热带农业生态过程重点实验室,洞庭湖湿地生态观测研究站,长沙 410125)

\begin{abstract}
摘 要: 本文研究洞庭湖三种分布于不同水位的主要群落(荻、苔草、曧草) 土壤种子库大小组成、垂直分布特征及其地表 植被的相关性. 结果表明: 荻群落土壤种子库密度最高, 为 44656 粒 $/ \mathrm{m}^{2}$, 苔草群落的最低, 为 15146 粒 $/ \mathrm{m}^{2}$, 虉草群落的居 中, 为 31725 粒 $/ \mathrm{m}^{2}$. 种子主要分布于土壤表层 $(0 \sim 5 \mathrm{~cm})$, 且随土壤剖面深度的增加而迅速递减. 三种群落湿地种子库由 53 种植物组成,分属 18 科 39 属, 其中多年生物种 20 种, 一或二年生物种 33 种. 在荻、苔草和曧草三种群落中, 种子库的 多年生物种分别占 $29.9 \% 、 35.2 \%$ 和 $38.0 \%$,物种多样性指数分别为 $0.76 、 0.70$ 和 0.72 ; 地表植被物种多样性指数分别 为 $0.53 、 0.17$ 和 0.45 , 土壤种子库与相应地表植被相似性系数分别为 $0.40 、 0.28$ 和 0.52 . 可见,在洞庭湖这一通江湖泊 湿地,多年生地表植被所产生的种子对土壤种子库大小贡献相对有限, 种子库可能主要通过其它途径 (如水的流动作用) 输人.
\end{abstract}

关键词: 土壤种子库;地表植被;洞庭湖;相关性

\section{Characteristics of soil seed bank and its relationship with aboveground vegetation in Lake Dongting}

\section{HOU Zhiyong, CHEN Xinsheng, XIE Yonghong \& LI Xu}

(Lake Dongting Station for Wetland Ecosystem Observation and Research, Key Laboratory for Agro-ecological Processes in Subtropical Region, Institute of Subtropical Agriculture, Chinese Academy of Sciences, Changsha 410125, P. R. China)

\begin{abstract}
The size, composition, vertical distribution and species diversity of seed bank as well as its relationship with aboveground vegetation were studied in three dominant plant communities (Miscanthus sacchariflorus, Carex sp. , and Phalaris arundinacea) distributing with different water levels in Lake Dongting. The density of seed bank was highest in M. sacchariflorus (44656 seeds $/ \mathrm{m}^{2}$ ), followed by P. arundinacea $\left(31725\right.$ seeds $/ \mathrm{m}^{2}$ ) and lowest in Carex sp. (15146 seeds $\left./ \mathrm{m}^{2}\right)$. Seeds in the seed bank distributed mainly within $0 \sim 5 \mathrm{~cm}$ soil layer and decreased rapidly along with the soil depth. The seed banks of the three communities were composed of 53 species belonging to 18 families, 39 genera. Among them, 20 species were perennial while 33 were annual or biannual. The proportions of perennial species were $29.9 \%, 35.2 \%$ and $38.0 \%$ in the soil seed bank of $M$. sacchariflorus, $C$. sp. and $P$. arundinacea communities, respectively. The diversity indexes of seed bank and aboveground vegetation were 0.76 and 0.53 in M. sacchariflorus, 0.70 and 0.17 in $C$. sp., 0.72 and 0.45 in $P$. arundinacea, respectively. The similarity indexes between seed bank and aboveground vegetation were 0.28 in C. sp., 0.40 in M. sacchariflorus and 0.52 in $P$. arundinacea, respectively. The diversity index of seed bank was higher than that of aboveground vegetation and the similarity was relatively low. Therefore, perennial aboveground vegetation has limited contribution to the soil seed bank in large Yangtze-connected lake wetlands, where seeds might be mainly imported into seed bank through other pathways, such as water flow.
\end{abstract}

Keywords: Soil seed bank; aboveground vegetation; Lake Dongting; similarity

地表植被是土壤种子库主要来源, 其生长发育状况及繁殖能力直接影响着土壤种子库的组成、大小及

* 国家重点基础研究发展计划“973”项目(2012CB417005)、中国科学院知识创新工程重要方向性项目 (KZCX2-YW435 ) 和国家自然科学基金项目 (30770362) 联合资助. 2011-06-02 收稿; 2011-10-17 收修改稿. 侯志勇, 男, 1982 年生, 硕士, 实习研究员; E-mail:hzy2005@126. com.

** 通信作者; E-mail: yonghongxie@163.com. 
其季节动态. 同时, 土壤种子库作为种源储备库和植物群落的重要组成部分, 通过种子萌发形成实生苗参与 地表植被的自然更新, 直接影响着地上植物群落的组成与结构; 尤其当植物群落遭受灾难性破坏时, 种子库 能起到缓冲作用而减少种群灭绝的几率 ${ }^{[1-3]}$. 湿地植物的繁殖、发育与更新常常受水位的制约, 而种子库是 湿地植被结构、植物多样性与植物有性繁殖能力以及对局部环境与水位变化适应的综合反映, 揭示湿地土 壤种子库的数量特征、种类组成、空间分布格局以及与地上植被的关系等是认识湿地植被繁殖与依靠种子 自然更新的重要途径. 当前, 国内外许多学者针对沼泽 ${ }^{[4-5]}$ 、浅水湖泊 ${ }^{[6]}$ 、湖岸 ${ }^{[7]}$ 和河流 ${ }^{[8]}$ 等类型的淡水湿地 种子库开展研究, 而以通江湖泊为对象的研究很少. 与上述湿地类型相比, 通江湖泊在保护湖泊的自然属 性、生态系统的稳定性、减缓湖泊的萎缩以及提高湖泊防蓄洪能力等方面起着非常重要的作用.

洞庭湖为我国第二大淡水湖, 是长江中游仅存的两个典型通江湖泊之一, 其水位季节性变化明显, 涨水 为湖, 落水为洲, 承担着行洪调蓄、生态保育的重要功能, 在湿地生物多样性保护中发挥了极其重要的作用. 自 1990s 以来, 洞庭湖开始大规模种植杨树, 洲滩原貌被肆意改变, 原有群落生态系统遭到严重破坏, 调查对 比发现在南洞庭和西洞庭原有苔草群落正大面积消失, 生物多样性遭受严重破坏. 本文以洞庭湖湿地的三 种主要植被类型为对象, 开展湿地植被土壤种子库调查研究, 探讨洞庭湖湿地土壤种子库的基本特征及与 相应地表植被群落组成的关系, 以期为湿地植被保护、恢复和持续管理提供科学依据.

\section{1 研究区域与研究方法}

\section{1 研究区概况}

洞庭湖 $\left(28^{\circ} 30^{\prime} \sim 29^{\circ} 31^{\prime} \mathrm{N}, 111^{\circ} 40^{\prime} \sim 113^{\circ} 10^{\prime} \mathrm{E}\right)$ 位于湖南省东北部, 长江中游荆江段南岸, 为长江中下 游地区最为典型的通江湖泊, 承担着长江和湖南 “四水” (湘、资、沅、澧) 调蓄的重要任务, 素有 “长江之肾” 的美誉. 洞庭湖区为冲积平原, 平均海拔低于 $40 \mathrm{~m}$, 面积 $18780 \mathrm{~km}^{2}$, 天然湖泊面积 $2625 \mathrm{~km}^{2}$. 湖区属亚热带 季风性气候, 春夏冷暖气流交替频繁, 夏秋晴热少雨, 秋寒偏旱. 多年平均气温 $16.5 \sim 17.0^{\circ} \mathrm{C}, 1$ 月平均气温 $3.8 \sim 4.7^{\circ} \mathrm{C}, 7$ 月平均气温 $29^{\circ} \mathrm{C}$ 左右, 年平均降水量 $1250 \sim 1450 \mathrm{~mm}$, 无霜期 $260 \sim 280 \mathrm{~d}$, 年平均湿度 $80 \%$. 同时,受水位周期性波动的影响, 形成了开阔水面、沼泽、浅滩和低岸等复杂的地形地貌. 湿地生态条件的区 域差异性和生态过程的多变性,为洞庭湖发育多样的湿地植被类型提供了良好的条件.

洞庭湖湿地主要植被类型为水生植被、草甸、沼泽植被和常绿阔叶林植被; 在空间格局上呈现明显的带 状分布, 由水及陆总趋势为: 沉水植物群落 $\rightarrow$ 融草群落 $\rightarrow$ 辣苶 + 苔草群落 $\rightarrow$ 苔草群落 $\rightarrow$ 鸡婆柳 $\rightarrow$ 荻 + 芦苇 群落 $\rightarrow$ 美洲黑杨或旱柳群落. 湿地植物群落的物种组成以多年生草本植物为主, 其中最具代表性的为鬲草 (Phalaris arundinacea)、苔草 (Carex sp.)、荻(Miscanthus sacchariflorus) 等 $^{[9]}$.

\section{表 1 样地地理位置}

Tab. 1 Geographical location of sampling plots

\begin{tabular}{ccc}
\hline $\begin{array}{c}\text { 植被 } \\
\text { 群落 }\end{array}$ & 采样地 & 地理位置 \\
\hline 荻 & 团洲 & $29^{\circ} 19^{\prime} 26 \sim 29^{\prime \prime} \mathrm{N}, 112^{\circ} 48^{\prime} 25 \sim 33^{\prime \prime} \mathrm{E}$ \\
荻 & 双丰 & $29^{\circ} 01^{\prime} 38 \sim 46^{\prime \prime} \mathrm{N}, 112^{\circ} 50^{\prime} 16 \sim 25^{\prime \prime} \mathrm{E}$ \\
荻 & 北洲子 & $29^{\circ} 09^{\prime} 44 \sim 50^{\prime \prime} \mathrm{N}, 112^{\circ} 43^{\prime} 44 \sim 45^{\prime \prime} \mathrm{E}$ \\
苔草 & 麻塘 & $29^{\circ} 14^{\prime} 52 \sim 55^{\prime \prime} \mathrm{N}, 113^{\circ} 04^{\prime} 10^{\prime \prime} \sim 114^{\circ} 0^{\prime} 0^{\prime \prime} \mathrm{E}$ \\
苔草 & 中洲 & $29^{\circ} 04^{\prime} 35 \sim 42^{\prime \prime} \mathrm{N}, 112^{\circ} 59^{\prime} 0 \sim 3^{\prime \prime} \mathrm{E}$ \\
苔草 & 鹿角 & $29^{\circ} 08^{\prime} 6 \sim 13^{\prime \prime} \mathrm{N}, 113^{\circ} 00^{\prime} 44 \sim 49^{\prime \prime} \mathrm{E}$ \\
䰙草 & 北洲子 & $29^{\circ} 10^{\prime} 7 \sim 24^{\prime \prime} \mathrm{N}, 112^{\circ} 47^{\prime} 45 \sim 53^{\prime \prime} \mathrm{E}$ \\
融草 & 双丰 & $29^{\circ} 01^{\prime} 30 \sim 41^{\prime \prime} \mathrm{N}, 112^{\circ} 48^{\prime} 10 \sim 23^{\prime \prime} \mathrm{E}$ \\
鷊草 & 麻塘 & $29^{\circ} 14^{\prime} 49 \sim 55^{\prime \prime} \mathrm{N}, 113^{\circ} 04^{\prime} 19 \sim 20^{\prime \prime} \mathrm{E}$ \\
\hline
\end{tabular}

\section{2 研究方法}

1.2.1 土壤种子库取样 本文以分布于不同水 位梯度的曧草、苔草、荻三种湿地植被群落作为 研究对象, 荻群落分布最高, 苔草群落次之, 融 草群落最低 ${ }^{[9]} .2007$ 年 10 月当洪水完成对湿地 种子库的再次输人后各群落类型分别按相同水 位梯度选取 3 个微地形一致的区域作为样区 (表 1 ). 在每个样区内按直线每隔 $50 \mathrm{~m}$ 设一个 $1 \mathrm{~m} \times 1 \mathrm{~m}$ 的小样方, 共计 15 个, 记录 GPS 位 点. 考虑到湿地土壤种子库数量随着土壤深度 的递增而减少, 当深度达 $8 \sim 12 \mathrm{~cm}$ 时甚至减少 到 $0^{[10-11]}$, 采用网格法在每个小样方内用土壤种 子库取样器 (21 $\left.\mathrm{cm}^{2}\right)$ 采集 20 个土芯, 然后分 3 层 $(0 \sim 2 \mathrm{~cm} 、 2 \sim 5 \mathrm{~cm} 、 5 \sim 10 \mathrm{~cm})$ 将同层混合装

人保鲜袋, 封好袋口, 及时带回实验室备用. 所得样品共计 405 份.

1.2 .2 萌发试验 将相同样区的同层土样混匀后于室内自然风干, 破碎后用孔径为 $0.2 \mathrm{~mm}$ 的网篮耖洗 ${ }^{[12]}$. 
然后将土样平铺于装有 $3 \mathrm{~cm}$ 沙子 (经 $120^{\circ} \mathrm{C}$ 烘箱处理 $24 \mathrm{~h}$, 确保无存活种子存在) 的萌发盒 $(25 \mathrm{~cm} \times 20 \mathrm{~cm}$ $\times 5 \mathrm{~cm}$ ) 中, 土样厚度为 $1 \mathrm{~cm}$, 重复 5 次, 放置于恒温恒湿人工气候室 (温度 $25^{\circ} \mathrm{C}$, 湿度 $60 \%$ ) 内萌发. 萌发过 程中每天加水 2 次以保持土样湿润. 实验开始 $6 \mathrm{~d}$ 后种子开始萌发, 萌发的物种种类及数量每星期记录 1 次. 幼苗一经鉴定即移走, 暂不能鉴定的幼苗移栽于培养箱中培养至可鉴定为止. 2008 年 7 月底不再有新的 种子萌发,继续观察 1 个月后结束实验,历时 $135 \mathrm{~d}$.

1.2.3 地表植被调查 2008 年 5 月初, 按种子库取样 GPS 位点进行植被调查, 即在各个种子库采样区按原 采样带每隔 $10 \mathrm{~m}$ 设置 $1 \mathrm{~m} \times 1 \mathrm{~m}$ 小样方一个, 共计 15 个, 记录植被盖度、高度、物种数及每个物种的种子数 等群落特征.

1.2.4 数据分析 种子库密度: 将萌发试验的统计结果按参试篮取土样占原篎取土样的比例及取样面积大 小换算为 $1 \mathrm{~m}^{2}$ 的种子数量; 种子库中植物生活型: 参照《植物群落学》所采用的生活型系统 ${ }^{[13]}$, 将记录到的 植物种分为多年生草本植物、一或二年生草本植物两种类型, 分别计算每一类型植物占植物种总数的百 分比.

种子库物种的多样性指数: 根据各种子库中物种及其种子数量, 采用 Simpson 多样性指数 $(D)^{[14]}$ 分析 种子库物种多样性指数. 计算公式如下: $D=1-\sum_{i=1}^{s} \frac{N_{i}\left(N_{i}-1\right)}{N(N-1)}$; 式中, $N$ 为样本数; $N_{i}$ 为 $i$ 种的个体数; $S$ 为 物种数. 地表植被的物种多样性指数计算同种子库.

种子库与地表植被的相似性系数采用 Sorensen 系数 $(S C)$ 计算 ${ }^{[15]}: S C=2 \omega /(a+b)$, 式中, $a$ 为土壤种子 库中物种数, $b$ 为地表植被物种数, $\omega$ 为种子库和地表植被共有物种数.

种子库物种百分比:计算种子库中每一种植物种子数占所有物种种子总数的百分比.

\section{3 统计处理}

数据处理采用统计软件包 SPSS 10.0 和 Excel 2003 进行. 土壤种子库三种群落类型及土壤层次间密度 差异利用单因素方差分析进行比较,多重比较采用 Duncan 检验,显著度水平为 0.05 .

\section{2 结果及分析}

\section{1 地表植被构成}

荻群落由 12 科 16 种植物构成, 平均密度为 24 株 $/ \mathrm{m}^{2}$, 平均株高为 $3.48 \mathrm{~m}$, 主要伴生种有附地菜 (Trigonotis peduncularis)、猪殊殊 (Galium aparine)、水苏 (Stachys japonica)、鸡矢藤 (Paederia scandens)、芦苇 (Phragmites australis); 融草群落由 9 科 14 种植物构成, 平均密度为 241 株 $/ \mathrm{m}^{2}$, 平均株高为 $0.93 \mathrm{~m}$, 主要伴 生种有通泉草(Mazus japonicus)、野胡萝卜 (Daucus carota)、茥草(Beckmannia syzigachne)、酸模( Rumex aceto$s a$ )、中华小苦荬 (Ixeridium chinense) ; 苔草群落由 7 科 8 种植物构成, 平均密度为 1375 株 $/ \mathrm{m}^{2}$, 平均株高为 $0.71 \mathrm{~m}$, 主要伴生种有苔草 (Carex sp. )、委陵菜 (Potentilla chinensis)、紫云英(Astragalus sinicus)、细柄卫矛 (Euonymus euscaphis) 、中华小苦荬. 群落间植被形态差异显著, 荻群落的建群种个体最大, 群落密度最小; 融 草群落的建群种次之, 苔草群落的建群种个体最小, 群落密度最大.

\section{2 种子库种子大小及分布}

洞庭湖不同植被类型湿地种子库密度差异显著 $(P<0.05)$, 荻群落的种子库平均密度最大, 为 44656 粒 $/ \mathrm{m}^{2}$; 融草群落次之, 为 31725 粒 $/ \mathrm{m}^{2}$; 最小的为苔草群落, 为 15146 粒 $/ \mathrm{m}^{2}$ (表 2). 种子占总种子数的比例 在不同土壤剖面为: 荻、苔草、虉草群落 $0 \sim 2 \mathrm{~cm}$ 分别为 $63 \% 、 51 \% 、 56 \% ; 2 \sim 5 \mathrm{~cm}$ 分别为 $27 \% 、 35 \% 、 25 \%$; $5 \sim 10 \mathrm{~cm}$ 分别为 $10 \% 、 14 \% 、 19 \%$, 结果表明种子占种子库的比例随土壤剖面深度的增加而骤减, 同时种子 主要分布于 $0 \sim 5 \mathrm{~cm}$ 土壤中.

\section{3 种子库植物种类及生活型}

三种植被类型种子库中, 共统计到 49 种植物, 分属 17 科, 以禾本科植物最多 (12 种), 玄参科 (7 种)、十 字花科 (6 种) 次之, 其它如紫草科、藜科、茜草科、豆科等各为 1 种 (表 2). 荻群落中共计 29 个物种, 分属 12 科, 以禾本科最多 (7 种), 菊科次之 (6 种); 种子密度最大的植物种为碎米芥, 其次为附地菜. 苔草群落土壤 种子库中共 19 个物种, 分属 8 科, 以禾本科最多 (5 种), 菊科和玄参科次之 (3 种); 种子库密度最大的植物 
种为蚊母草, 其次为碎米芥. 融草群落种子库含 23 种植物, 分属 7 科, 以禾本科最多 ( 7 种), 十字花科和莎草 科次之 (3 种); 种子密度最大的植物为蚊母草, 其次为看麦娘 (Alopecurus aequalis). 可见, 种子库以禾本科植 物占优势, 但不同植被类型的优势物种存在差异.

生活型结果分析表明, 三种植被类型种子库中多年生物种共计 20 种, 占植物种类的 $37.7 \%$; 一或二年 生物种 33 种, 占 $62.3 \%$. 在荻群落、苔草群落、翮草群落土壤种子库中, 一或二年生草本植物种子占总种子 数的比例分别为 $70.1 \% 、 64.8 \%$ 和 $62 \%$, 而多年生草本植物分别仅为 $29.9 \% 、 35.2 \%$ 和 $38 \%$. 可见, 土壤种 子库以一或二年生植物为主.

表 2 不同植被类型土壤种子库主要物种及种子密度 $\left(\right.$ 粒 $\left./ \mathrm{m}^{2}\right)$ *

Tab. 2 Major plant species and seed densities of seed banks of different vegetations

\begin{tabular}{|c|c|c|c|c|c|c|c|c|c|}
\hline 植物种 & $\begin{array}{c}\text { 生活 } \\
\text { 型 }\end{array}$ & $\begin{array}{c}\text { 荻群 } \\
\text { 落 }\end{array}$ & $\begin{array}{l}\text { 苔草 } \\
\text { 群落 }\end{array}$ & $\begin{array}{l}\text { 曧草 } \\
\text { 群落 }\end{array}$ & 植物种 & $\begin{array}{c}\text { 生活 } \\
\text { 型 }\end{array}$ & $\begin{array}{c}\text { 荻群 } \\
\text { 落 }\end{array}$ & $\begin{array}{l}\text { 苔草 } \\
\text { 群落 }\end{array}$ & $\begin{array}{l}\text { 蒚草 } \\
\text { 群落 }\end{array}$ \\
\hline 窃衣 Torilis scabra & $\mathrm{AH}$ & 1147.5 & 11 & 0 & 荩草 Arthraxon hispidus & $\mathrm{AH}$ & 85 & 0 & 0 \\
\hline 附地菜 Trigonotis peduncularis & $\mathrm{AH}$ & 11517.5 & 0 & 0 & 小飞蓬 Erigeron canadensis & $\mathrm{PH}$ & 212.5 & 0 & 0 \\
\hline 小藜 Chenopodium serotinum & $\mathrm{AH}$ & 4292.5 & 0 & 0 & 香附子 Cyperus rotundus & $\mathrm{PH}$ & 127.5 & 0 & 0 \\
\hline 看麦娘 Alopecurus aequalis & $\mathrm{AH}$ & 552.5 & 0 & 7970 & 婆婆纳 Veronica didyma & $\mathrm{AH}$ & 425 & 0 & 0 \\
\hline 碎米芥 Cardamine hirsuta & $\mathrm{AH}$ & 15045 & 5095 & 3984 & 日本看麦娘 Alopecurus japonicus & $\mathrm{AH}$ & 0 & 127.5 & 1593 \\
\hline 猪殊殊 Galium aparine & $\mathrm{AH}$ & 893 & 0 & 0 & 苔草 Carex sp. & $\mathrm{PH}$ & 42.5 & 127.5 & 159.4 \\
\hline 球果蔊菜 Rorippa globosa & $\mathrm{AH}$ & 297.5 & 0 & 0 & 早熟禾 Poa аппиа & $\mathrm{AH}$ & 0 & 85 & 1275 \\
\hline 酸模 Rumex acetosa & $\mathrm{PH}$ & 42.5 & 0 & 7 & 繁缕 Stellaria media & $\mathrm{AH}$ & 0 & 0 & 79.7 \\
\hline 石龙芮 Ranunculus sceleratus & $\mathrm{AH}$ & 795.5 & 0 & 0 & 齿果酸模 Rumex dentatus & $\mathrm{PH}$ & 0 & 0 & 79.7 \\
\hline 鼠麭草 Gnaphalium affine & $\mathrm{AH}$ & 1530 & 138.5 & 0 & 双穗雀稗 Paspalum paspaloides & $\mathrm{PH}$ & 0 & 42.5 & 79.7 \\
\hline 葡茎通泉草 Mazus miquelii & $\mathrm{AH}$ & 127.5 & 1635.5 & 0 & 草地早熟禾 Poa pratensis & $\mathrm{PH}$ & 0 & 127.5 & 0 \\
\hline 泥胡菜 Hemistepta lyrata & $\mathrm{PH}$ & 127.5 & 0 & 0 & 水茫草 Limosella aquatica & $\mathrm{AH}$ & 0 & 127.5 & 0 \\
\hline 蔊菜 Rorippa indica & $\mathrm{AH}$ & 680 & 0 & 0 & 苦蘵 Physalis angulata & $\mathrm{AH}$ & 85 & 0 & 0 \\
\hline 马唐 Digitaria sanguinalis & $\mathrm{AH}$ & 42.5 & 0 & 79.7 & 菌草 Beckmannia erucaeformis & $\mathrm{AH}$ & 127.5 & 0 & 0 \\
\hline 野胡萝卜Daucus carota & $\mathrm{PH}$ & 170 & 11 & 159.4 & 刚毛䒬荠 Heleocharis valleculosa & $\mathrm{PH}$ & 0 & 0 & 79.7 \\
\hline 风花菜 Rorippa globosa & PH & 0 & 948 & 398.4 & 小叶珍珠菜 Lysimachia parvifolia & $\mathrm{AH}$ & 0 & 0 & 159.4 \\
\hline 北美独行菜 Lepidium virginicum & $\mathrm{AH}$ & 0 & 88 & 0 & 水马齿 Callitriche palustris & $\mathrm{AH}$ & 0 & 0 & 797 \\
\hline 蚊母草 Veronica peregrina & $\mathrm{AH}$ & 0 & 5944 & 10956 & 水苦荬 Veronica undulata & $\mathrm{AH}$ & 42.5 & 0 & 79.7 \\
\hline 白顶早熟禾 Poa acroleuca & $\mathrm{AH}$ & 255 & 110 & 1593 & 止血马唐 Digitaria ischaemum & $\mathrm{AH}$ & 0 & 0 & 79.7 \\
\hline 紫云英 Astragalus sinicus & $\mathrm{AH}$ & 0 & 195 & 1797 & 鵰草 Phalaris arundinacea & $\mathrm{PH}$ & 0 & 0 & 159.4 \\
\hline 蛇莓委陵菜 Potentilla centigrana & PH & 0 & 140 & 0 & 针萄 Eleocharis valleculosa & $\mathrm{PH}$ & 0 & 0 & 159.4 \\
\hline 通泉草 Mazus japonicus & $\mathrm{AH}$ & 0 & 0 & 0 & 委陵菜 Potentilla chinensis & $\mathrm{PH}$ & 0 & 170 & 0 \\
\hline 黄婍菜 Youngia japonica & $\mathrm{AH}$ & 1105 & 22 & 0 & 毛莨 Ranunculus japonicus & $\mathrm{PH}$ & 0 & 0 & 0 \\
\hline 荠菜 Capsellabursa pastoris & $\mathrm{AH}$ & 3656.5 & 0 & 0 & 荻 Miscanthus sacchariflorus & $\mathrm{PH}$ & 0 & 0 & 0 \\
\hline 卷耳 Cerastium arvense & $\mathrm{AH}$ & 722.5 & 0 & 0 & 地黄 Rehmannia glutinosa & $\mathrm{PH}$ & 0 & 0 & 0 \\
\hline 棒头草 Polypogon fugax & $\mathrm{AH}$ & 382.5 & 0 & 0 & 冷水花 Pilea notata & $\mathrm{PH}$ & 0 & 0 & 0 \\
\hline 苦实菜 Chorisis repens & $\mathrm{PH}$ & 127.5 & 0 & 0 & 合计 53 种 & & 44656 & 15146 & 31725 \\
\hline
\end{tabular}

$* \mathrm{PH}$ : 多年生草本植物; $\mathrm{AH}$ :一或二年生草本植物.

\section{4 地表植被与种子库的关系}

将不同植被类型地表植被盖度较大的前 5 种植物的分盖度与总盖度的比例与土壤种子库相应物种种 子占所有物种种子总数的比例对照发现: 在荻群落中统计到 16 种植物, 作为建群种的附地菜、猪殎殊在土 壤中分别占 $26 \%$ 和 $2 \%$ 的种子, 其它物种如芦苇、鸡矢藤、水苏等在种子库中未统计到 (图 1a); 在苔草群落 中统计到 8 种, 作为建群种的苔草、委陵菜、紫云英在土壤种子库中都出现, 其它两个物种细柄卫矛、中华小 苦荬在种子库中未发现 (图 $1 \mathrm{~b}$ ); 在曧草群落中统计到 14 种, 主要建群种植物曧草、紫云英、野胡萝卜在土壤 种子库中出现,其它 2 个物种通泉草、䓟草在种子库中没有发现 (图 1c). 
种子库和地表植被的物种多样性指数在荻群落中分别为 0.76 和 0.53 ,物种相似性系数为 0.40 ; 苔草群 落中分别为 0.70 和 0.17 , 物种相似性系数为 0.28 ; 茼草群落中分别为 0.72 和 0.45 , 物种相似性系数为 0.52 , 种子库的物种多样性普遍高于地表植被, 地表植被与种子库物种相似性系数除曧草群落的相对较高 外,其它两种植被类型较低.

叉地表植被 口种子库
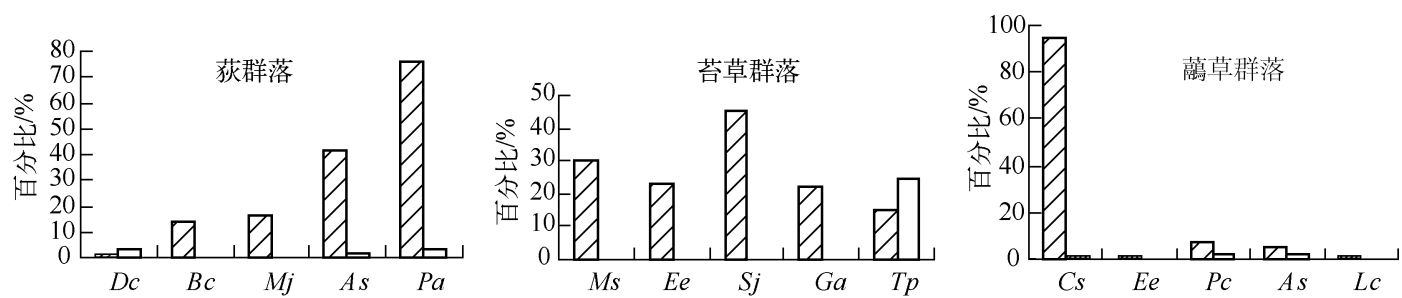

图 1 不同植被类型土壤种子库与地表植被优势物种百分比的比较 $(M s$ : 荻 $; E e$ : 细柄卫矛; $S j:$ 水苏 $; T p$ : 附地菜; $G a$ : 猪殊殊 $; C s$ : 苔草 $; P c$ : 委陵菜; $A s$ : 紫云英; $P a$ : 翮草; $D c$ : 野胡萝卜; $M j$ : 通泉草; $L c$ : 中华小苦荬 $; B c$ : 茥草)

Fig. 1 Comparisons between composition of dominant species in seed banks and aboveground vegetations

\section{3 讨论}

\section{1 不同植被类型的种子库大小}

研究结果表明洞庭湖湿地分布于不同水位下的植被群落土壤种子库大小呈明显的“V”型结构, 分布于 高水位区的荻群落种子库密度最高, 低水位区的曧草群落次之, 中水位区的苔草群落最低, 说明水位和植被 类型对种子库大小的形成具有重要作用.

土壤种子库密度可能与所处地理位置水文因子的变化有着密切关系. 有研究表明,弱的水文波动有利 于种子的沉淀 ${ }^{[16-18]}$, 且水位变化高频区的湿地种子库物种丰富度高于低频区, 物种组成更复杂 ${ }^{[19]}$, 表明水文 波动频率是影响土壤种子库大小和组成的重要因素之一. 此外, 退耕湿地土壤种子库大小与水文因子作用 时间强度有密切的关系 ${ }^{[20]}$. 洞庭湖水位季节性波动明显, 湖水始涨于 4 月,7-8 月最高, 11 月至翌年 5 月为 枯水期. 低水位区每年受水文变化影响期最长, 中水位区次之, 高水位区最短. 且受洪水 (6-9 月) 前雨水冲 刷影响, 高、中水位区的种子将随雨水的流动而沉积于低水位区. 可见, 水文因子对低水位区作用最大, 有利 于种子的沉积.

植物群落形态和物种组成也可能是主导土壤种子库大小的因子之一. 荻、苔草、曧草 3 种群落植被形态 和物种组成差异显著, 荻群落的生物多样性和丰富度最高, 建群种个体最大, 群落密度最小; 曧草群落次之, 苔草群落的生物多样性、丰富度、个体最小, 群落密度最大. Nishihiro 等研究发现湿地沉积物中携带大量的种 子 $^{[17]}$. 洪水中苔草易倒伏, 在地表形成一个不利于沉积物堆积的光滑叶层, 而荻和鬲草个体大且密度相对较 小, 在洪水中能挺立不倒伏相对更有利于沉积物形成. 因此, 荻、曧草群落的植被形态有利于在洪水期间促 进种子输人土壤种子库, 这可能是导致荻和融草群落土壤种子库比苔草群落大的原因之一. 群落的物种多 样性和丰富度明显高于苔草群落, 群落中一或二年生物种数也明显高于苔草群落, 这些湿地植物为避免洪 水的直接伤害通常会改变生命周期的长短来适应环境的变化 ${ }^{[21]}$, 如野胡萝卜、泥湖菜、风花菜等都能在洪水 前 (5月中旬) 完成生活史, 种子进人土壤种子库. 因此, 荻群落丰富的一或二年生植物种子构成了土壤种子 库的主要来源, 这可能也是荻群落比苔草群落密度大的原因之一. 可见, 洞庭湖湿地种子库的大小和组成是 水文因子、植被形态及群落物种组成共同作用的结果.

\section{2 种子库与地表植被的相似性}

关于种子库与地表植被物种组成的关系, 有两种相反的结论: 一些研究表明不同植被类型斑块中的种 子库能很好地反映地上植被的物种组成 ${ }^{[22]}$; 另一些研究则表明两者差异较大 ${ }^{[23-24]}$, 土壤种子库不能很好地 反映出地表植被的物种组成, 本研究结果支持这一结论. 
造成种子库与地表植被物种组成差异的原因是多方面的. 第一, 实验或野外生境条件难以满足所有物 种种子萌发的适宜条件, 从而低估了种子库的物种组成或种子不能萌发而不能参与植被组成或更新. Dessaint 等指出, 许多湿地物种萌发前需要经历休眠阶段 ${ }^{[25]}$, 所以在种子库萌发前进行低温处理将利于种子 萌发. Sarah 研究发现种子库的萌发和水位有密切关系, 水淹条件下种子库萌发物种数比湿润条件下要少很 多 ${ }^{[26]}$. Leck 等研究表明,一些湿地物种的萌发需要满足特定的条件 ${ }^{[27]}$. Cresswell 等发现, 许多湿地物种需要 直接暴露于阳光下才能萌发 ${ }^{[28]}$, 植被对阳光的遮挡影响了野外条件下的种子萌发. 本研究的三种植被中苔 草群落密度非常大, 最高盖度达 $100 \%$. 这使得地表面的光照强度非常微弱. 在洪水后其地上部分倒伏, 在地 表面形成一层调落物. 这种小生境条件不利于其它物种的生长和种子萌发, 导致群落种子库中的一些物种 无法参与植被组成或更新. 第二, 本研究三种植物群落的建群种均为多年生植物, 这些多年生植物主要通过 无性繁殖产生后代来维持和更新种群, 同时这些多年生植物虽能产生种子但能有效进人土壤种子库及能萌 发的种子数量有限. 在洞庭湖湿地苔草 5 月刚完成生活史就进入洪水期, 由于种子轻盈, 水流淹没处苔草种 子会在水面形成漂浮层,随洪水流失; 荻及芦苇作为一种重要的经济植物其花果期为 9-11 月,11 月开始被 收割, 许多种子尚未成熟或未传播就被收获, 大量的种子不能进人土壤种子库, 同时有研究表明芦苇种子萌 发适宜温度为 $20 \sim 35^{\circ} \mathrm{C}$, 其他温度不萌发, 萌发温度范围较窄 ${ }^{[29]}$, 对种子库贡献有限. 可见, 种子库主要是 通过一或二年生植物或通过种子扩散等外源性输人为主,致使种子库的组成不能反映植被的组成. 最后, 湿 地特殊的环境,如洪水周期的不确定性,有助于种子的长距离传播.

从本研究可以看出,虽然种子库中物种种类、数量和 Simpson 多样性指数均高于地表植被,但有些存在 于地表植被中的物种在种子库中不存在, 且不同植被类型中种子库的物种组成差异很大, 在采用湿地种子 库移植恢复受损湿地植被时, 从物种多样性角度来说, 不仅要考虑移植地表植被的种子库, 也应考虑植被类 型的差异性.

\section{4 参考文献}

[ 1 ] Kalisz S, Peek MA. Extinction dynamics, population growth and seed banks an example using an age structured annual. Oecologia , 1993, 95: 314-320.

[2] 赵丽娅, 李锋瑞, 张 华等. 科尔沁沙地围封沙质草甸土壤种子库特征的研究. 生态学杂志, $2004,23(2)$ : $45-49$.

[ 3 ] 罗 辉, 王克勤. 金沙江干热河谷山地植被恢复区土壤种子库和地上植被研究. 生态学报, 2006, 26 (8): $2432-2442$.

[ 4 ] Johnson S. Effects of water level and phosphorus enrichment from marsh seed banks collected from northern Belize. Aquatic Botany, 2004, 79: 311-323.

[ 5 ] 刘贵华, 李 伟, 王相否等. 湖南茶陵湖里沼泽种子库与地表植被的关系. 生态学报, 2004, 24(3): 450-456.

[6] 徐 洋, 刘文治, 刘贵华. 生态位限制和物种位限制对湖滨湿地植物群落结构的影响. 植物生态学报, 2009, 33 (3) : 546-554.

[ 7 ] Grelsson G, Nilsson C. Vegetation and seed bank relationship on a lakeshore. Freshwater Biology, 1991, 26: 199-207.

[ 8 ] Leck MA. Seed bank and vegetation development in a created tidal freshwater wetland on the Delaware River, Trenton, New Jersey, USA. Wetlands, 2003, 23: 310-343.

[ 9 ] 谢永宏, 陈心胜. 三峡工程对洞庭湖湿地植被演替的影响. 农业现代化研究, 2008, 29(6) : 684-687.

[10] Bonis A, Lepart J. Vertical structure of seed banks and the impact of depth of burial on recruitment in two temporary marshes. Vegetatio, 1994, 12 : 127-139.

[11] Thompson K, Bakker JP, Beller RM. Soil seed banks of North-west Europe: Methodology density and longevity. Cambridge: Cambridge University Press, 1997.

[12] TerHeerdt GNJ, Verwei JGL, Bekker RM et al. An improved method for seed-bank analysis: Seedling emergence after removing the soil by sieving. Functional Ecology, 1996, 10: 144-151.

[13] 林 鹏. 植物群落学. 上海: 上海科学技术出版社, 1986: 256-261.

[14] 张金屯. 数量生态学. 北京: 科学出版社, 2004: 95 .

[15] Arroyo MTK, Lohengrin A, Castor CC. Persistent soil seed bank and standing vegetation at a high alpine site in the central 
Chilean Andes. Oecologia, 1999, 11 : 126-132.

[16] Cherry JA, Gough L. Temporary floating island formation maintains wetland plant species richness: The role of the seed bank. Aquatic Botany, 2006, 85: 29-36.

[17] Nishihiro J, Nishihiro MA, Washitani I. Assessing the potential for recovery of lakeshore vegetation species richness of sediment propagule banks. Ecological Research, 2006, 21 : 436-445.

[18] Peterson JE, Baldwin AH. Seedling emergence from seed banks of tidal freshwater wetlands: Response to inundation and sedimentation. Aquatic Botany, 2004, 78: 243-254.

[19] Capon SJ. Effects of flooding on seedling emergence from the soil seed bank of a large desert floodplain. Wetlands, 2007, 27: 904-914.

[20] 侯志勇, 谢永宏, 于晓英等. 洞庭湖青山垸退耕地不同水位土壤种子库特征. 应用生态学报, 2009, 20(6)：13231328.

[21] 罗文泊, 谢永宏, 宋凤斌. 洪水条件下湿地植物的生存策略. 生态学杂志, 2007, 26(10): 1478-1485.

[22] Kadlec RH. Overlandflow in wetlands: Vegetation resistance. Journal of Hydraulic Engineering, 1990, 116 ( 5 ): $691-706$.

[23] 王相否, 周 进, 李 伟等. 洪湖湿地退耕初期种子库的季节动态. 植物生态学报, 2003, 27(3): 352-359.

[24] Wilson AD. Relationships of marsh seed banks to vegetation patterns along environmental gradients. Freshwater Biology, 1993, 29: 361-370.

[25] Dessaint F, Chadoeu FR, Barralis G. Spatial pattern analysis of weed seeds in the cultivated soil seed bank. Journal of Applied Ecology, 1991, 28: $721-730$.

[26] Sarah J. Effects of water level and phosphorus enrichment on seedling emergence from marsh seed banks collected from northern Belize. Aquatic Botany, 2004, 79: 311-323.

[27] Leck MA, Simpson RL. Seed bank of a freshwater tidal wetland: turnover and relationship to vegetation change. American Journal of Botany, 1987, 74 : 360-370.

[28] Cresswell EG, Grime JP. Induction of a light requirement during seed development and its ecological consequences. Nature, 1981,291 : 583-585.

[29] 李有志. 小叶章和芦苇种子萌发以及幼苗生长对环境因子的响应研究 [学位论文]. 长沙: 湖南农业大学, 2007. 